\title{
A Bioinformatics Study to Detect the Genetic Characteristics of Vespa Hornets (Hymenoptera: Vespidae)
}

\author{
Hossam F. ABOU-SHAARA ${ }^{1 *} \quad$ Mona I. ELBANOBY ${ }^{2}$ \\ 1,2Department of Plant Protection, Faculty of Agriculture, Damanhour University, Damanhour, \\ 22516, EGYPT \\ e-mails: ${ }^{1 *}$ hossam.farag@agr.dmu.edu.eg, ${ }^{2}$ mona.elbanoby@agr.dmu.edu.eg \\ ORCID IDs: ${ }^{1 *} 0000-0001-7208-6526,{ }^{20000-0002-6814-3951 ~}$
}

\begin{abstract}
Hornets especially from genus Vespa can attack honey bee colonies, causing economic damages to beekeeping. Also, these hornets can cause damages to some crops. Basically, Vespa hornets occur in different parts of the world including Asia, North Africa, and Europe. Recently, the hornet, Vespa velutina, has invaded Europe and considered as a serious pest to beekeeping. This study aimed to investigate the genetic similarities between five Vespa hornets: V. orientalis, V. ducalis, V. mandarinia, $V$. affinis, and $V$. velutina depending on analyzing the sequences of mtDNA utilizing bioinformatics. The phylogenetic relationships, segments from the enzymatic digestion, open reading frames, and number of shared gene cluster families were investigated to detect the genetic similarities. Also, specific primers to discriminate between these hornets were designed and tested in silico. The potential infection of these hornets with similar pathogens was emphasized in light of the obtained results.
\end{abstract}

Key words: Honey bees, invasion, predators, genes, bioinformatics.

Abou-Shaara, H.F. \& Elbanoby, M.I. (2020). A bioinformatics study to detect the genetic characteristics of Vespa hornets (Hymenoptera: Vespidae). Journal of the Entomological Research Society, 22(3), 227-237. 


\section{INTRODUCTION}

Hornets belong to Vespa (Hymenoptera, Vespoidea, Vespidae) are considered as pests to honey bees and may cause damages to some crops. There are about 22 Vespa hornets (Archer, 2012), and these hornets are differed in their geographical distribution. The oriental hornets, Vespa orientalis Linnaeus, 1771, are existed in some Asian countries, North Africa, and some European countries, and accidently found in Mexico (Dvořák, 2006). Some hornet species distribute in Asia, e.g. Japan, China, Korea, including; the black-tailed hornet Vespa ducalis Smith, 1852 (predator to immature stages of paper wasp), the giant hornet Vespa mandarinia Smith, 1852 (a serious pest to agriculture in Japan, Matsuura \& Sakagami, 1973), the lesser banded hornet Vespa affinis Linnaeus, 1764 (predator to wasps and bees), and the Asian hornet Vespa velutina Lepeletier, 1836 (predator to honey bees, Tan et al, 2007). Recently, V. velutina was recorded in Iberian Peninsula (López, González, \& Goldarazena, 2011) and has invaded Europe (Grosso-Silva \& Maia, 2012; Monceau, Bonnard, \& Thiéry, 2014).

Previous studies on the oriental hornets have focused on many aspects including behavioral aspects and nest building (Ishay, 1976; Kugler, Motro, \& Ishay, 1979; Ishay et al, 1995), body properties and pheromones (Ishay, Ikan, \& Bergmann, 1965; Ikan, Gottlieb, Bergmann, \& Ishay, 1969; Raina \& Singh, 1996), venom components (Edery, Ishay, Lass, \& Gitter, 1972; Rosenberg, Ishay, \& Gitter, 1977; Schoeters \& Billen, 1995; Haim, Rimon, Ishay, \& Rimon, 1999). Some studies have focused on their damages to honey bee colonies (Taha, 2014) or crops (Al-Mahdawi \& Al-Kinani, 2011), and potential control strategies (Bacandritsos, Papanastasiou, Saitanis, \& Roinioti, 2006; Mahdi, Glaiim, \& Ibrahim, 2008) including possible biological trends (Haddad, Fuchs, Haddaden, \& Kopelke, 2005) and honey bee response (Papachristoforou et al, 2008; Papachristoforou, Rortais, Sueur, \& Arnold, 2011). Studies on other Vespa hornets have concentrated on similar aspects, for examples mating behavior of Vespa ducalis (Takahashi, Akimoto, Hasegawa, \& Nakamura, 2002), Venom of Vespa affinis (Sukprasert et al, 2013), behaviors and control of Vespa velutina (Abrol, 1994), and response of bees to Vespa mandarinia attack (Sugahara \& Sakamoto, 2009).

The mtDNA of some Vespa species have been sequenced including: $V$. mandarinia (Chen, Wei, \& Liu, 2016), V. orientalis (Haddad et al, 2017), V. affinis (Okuyama, Martin, \& Takahashi, 2017), V. ducalis (Kim, Jeong, Jeong, Kim, \& Kim, 2017), and V. velutina (Takahashi, Okuyama, Minoshima, \& Takahashi, 2018). The phylogenetic relationships between Vespa have been studied based on morphological characters (Perrard, Pickett, Villemant, Kojima, \& Carpenter, 2013) while few studies have focused on the genetic characteristics of these hornets. Indeed, bioinformatics can be effectively used to investigate the genetic relationships between organisms (Abou-Shaara \& Bayoumi, 2019). Therefore, this study aimed to investigate the genetic relationships between some Vespa hornets based on the mtDNA sequence with comparing genetic characteristics. This study expands the knowledge about genetic characteristics of Vespa hornets. 
A Bioinformatics Study to Detect the Genetic Characteristics of Vespa Hornets

\section{METHODS}

\section{Sequences of Vespa hornets}

The mtDNA sequences were downloaded from the National Center for Biotechnology Information (https://www.ncbi.nlm.nih.gov) and utilized in this study. The sequences were to Vespa orientalis (NCBI Reference Sequence: NC_034003.1, 16101 bp), Vespa ducalis (GenBank: KX950825.1, 15779 bp), Vespa affinis (NCBI Reference Sequence: NC_039134.1, 19109 bp), Vespa velutina (GenBank: AP017943.2, 16416 bp), and Vespa mandarinia (NCBI Reference Sequence: NC_027172.1, 15902 bp).

\section{Phylogenetic tree}

The sequences were aligned using ClustalW, then maximum likelihood method and the Jukes-Cantor model (Jukes \& Cantor, 1969) was used to construct the phylogenetic tree. This analysis was performed using MEGA7 (Kumar, Stecher, \& Tamura, 2016).

\section{Digest}

The available restriction enzymes at Genome Compiler 2.2.88 (http://www. genomecompiler.com) were used to digest the full sequences of Vespa hornets, and then simulated on gel using NEB $100 \mathrm{bp}$ ladder. The resulted fragments were compared to detect similarity aspects according to Abou-Shaara (2019a; 2019b).

\section{Open reading frames}

For each Vespa species, open reading frames (ORFs) were identified using Genome Compiler 2.2.88 with start codons of ATG or GTG or TTG or CTG and minimum length of amino acids of 100 , considering all frame types. The identified ORFs were compared between studied hornets to check the similarities.

\section{Shared gene cluster}

The number of shared gene clusters between the studied hornets was identified using OrthoVenn (http://www.bioinfogenome.net) utilizing proteins downloaded from Uniprot according to Abou-Shaara (2019a; 2019b).

\section{Primers to discriminate between Vespa hornets}

Primers were designed using Genome Compiler 2.2.88 utilizing the option of auto primer design. Primers were designed to amplify the region between 3000 to $3100 \mathrm{nt}$. The designed primers were tested using PCR simulation of SnapGene 4.2.6 software (from GSL Biotech; available at snapgene.com) to ensure the amplification of the target sequences.

\section{RESULTS AND DISCUSSION}

\section{Phylogenetic tree}

The phylogenetic tree (Fig. 1) shows the close relationships between $V$. velutina, $V$. mandarinia and $V$. ducalis while no close relationship was detected between $V$. 
orientalis and $V$. affinis. Previous studies support these findings, the phylogenetic analysis based on 45 morphological characters and molecular analysis showed the presence of close relationships between $V$. mandarinia and $V$. ducalis while the other three Vespa species were placed in different groups (Perrard et al, 2013). Based on the nucleotide sequences of the 13 protein-coding genes, close relationships between $V$. mandarinia, V. ducalis and V. affinis, were found (Okuyama et al, 2017; Takahashi et al, 2018), and between V. mandarinia and V. ducalis (Kim et al, 2017; Zhang, Huang, Chen \& Li, 2018). On the contrary with the current study, a close relationship was found between $V$. mandarinia and $V$. orientalis based on the un-gapped sequences of a multiple sequence alignment (Haddad et al, 2017), while V. orientalis and $V$. velutina were placed in close groups based on the nucleotide sequences of the 13 protein-coding genes (Takahashi et al, 2018). The present and previous studies confirm the high relatedness between $V$. mandarinia, and $V$. ducalis while the relationships between other Vespa species showed variation in relation to the analysis method. It is clear that the analysis method can result in different phylogenetic relationships between Vespa hornets.

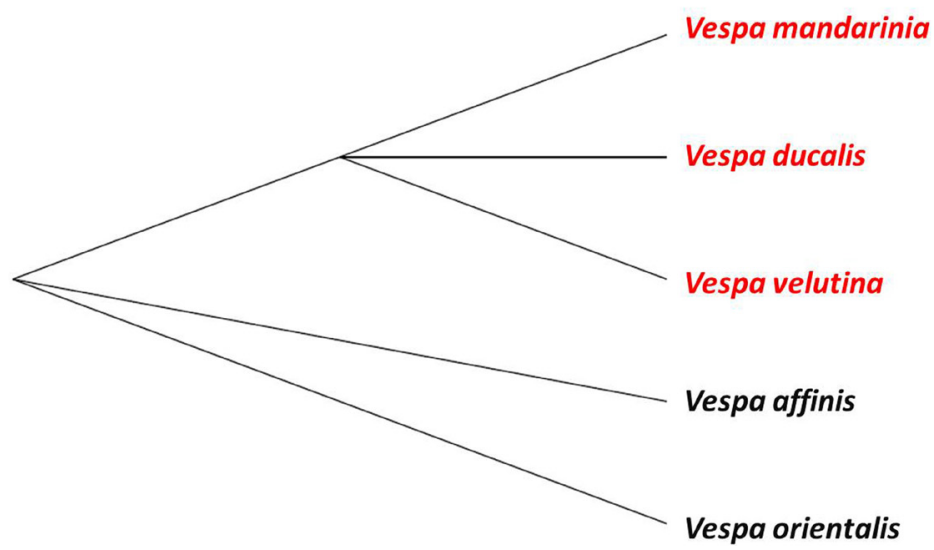

Fig. 1. The phylogenetic relationships between Vespa orientalis, Vespa ducalis, Vespa affinis, Vespa velutina, and Vespa mandarinia.

\section{Digest}

The fragments resulted from the enzymatic digestion of the mtDNA sequences of Vespa hornets are shown in Fig. 2. The number of fragments was 15, 14, 17, 16, and 21 for $V$. orientalis, $V$. ducalis, $V$. affinis, $V$. velutina and $V$. mandarinia, respectively. The number of similar fragments between $V$. mandarinia and the other hornets was 6,4 , 6 , and 9 fragments with $V$. velutina, $V$. affinis, $V$. ducalis, and $V$. orientalis, respectively. The closely related species $V$. mandarinia, $V$. velutina, and $V$. ducalis as shown from the phylogenetic tree had the same number of similar fragments. This supports the genetic relationships between these three hornets. In general, the presence of similar fragments among Vespa hornets is anticipated because they belong to the same family and genus. 
A Bioinformatics Study to Detect the Genetic Characteristics of Vespa Hornets

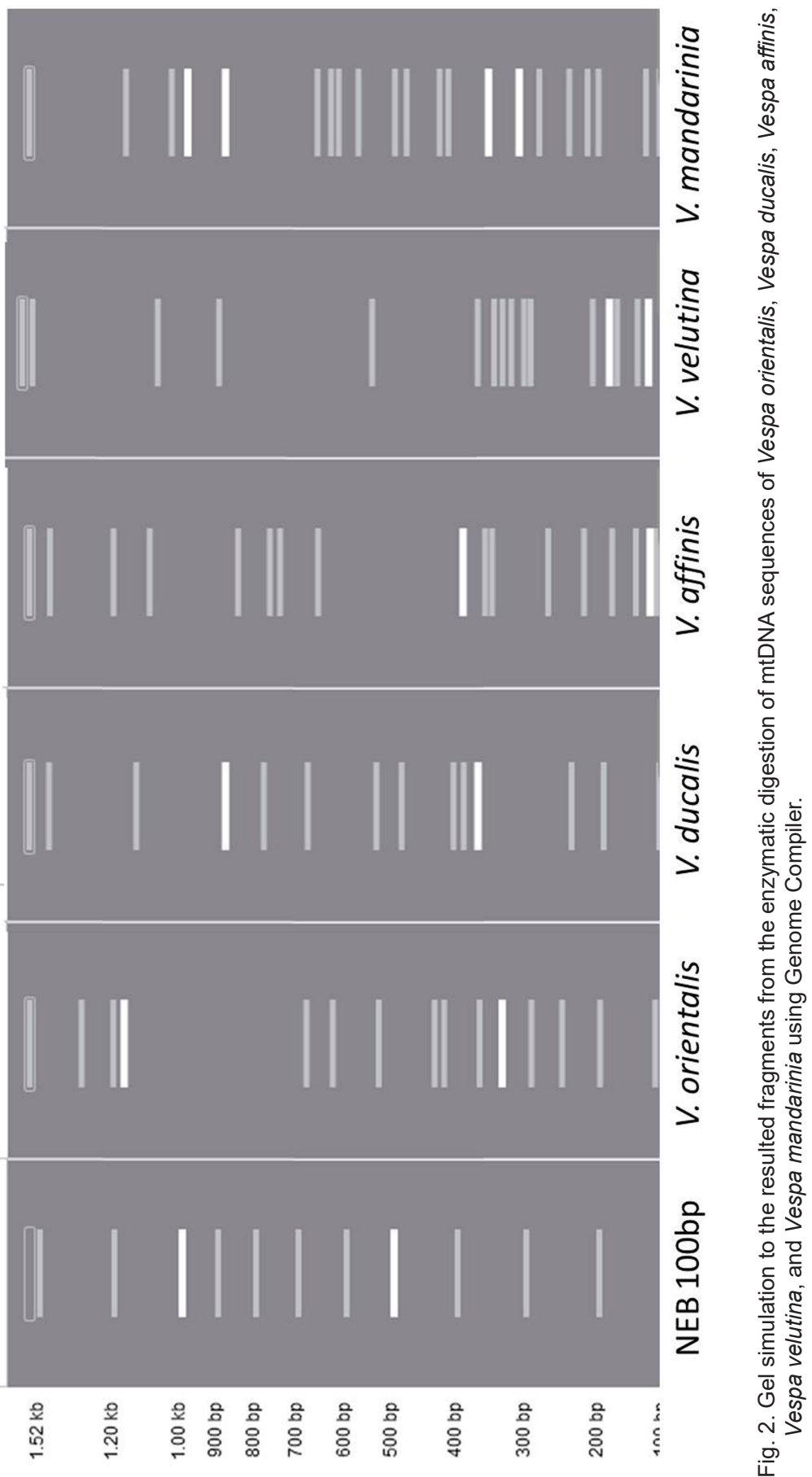




\section{Open reading frames}

The detected ORFs were somewhat similar between $V$. mandarinia, $V$. velutina, and $V$. ducalis unlike $V$. orientalis and $V$. affinis (Fig. 3). This finding supports the phylogenetic relationships detected based on the phylogenetic tree, and suggests the low number of ORFs with 100 amino acids in the studied hornets.
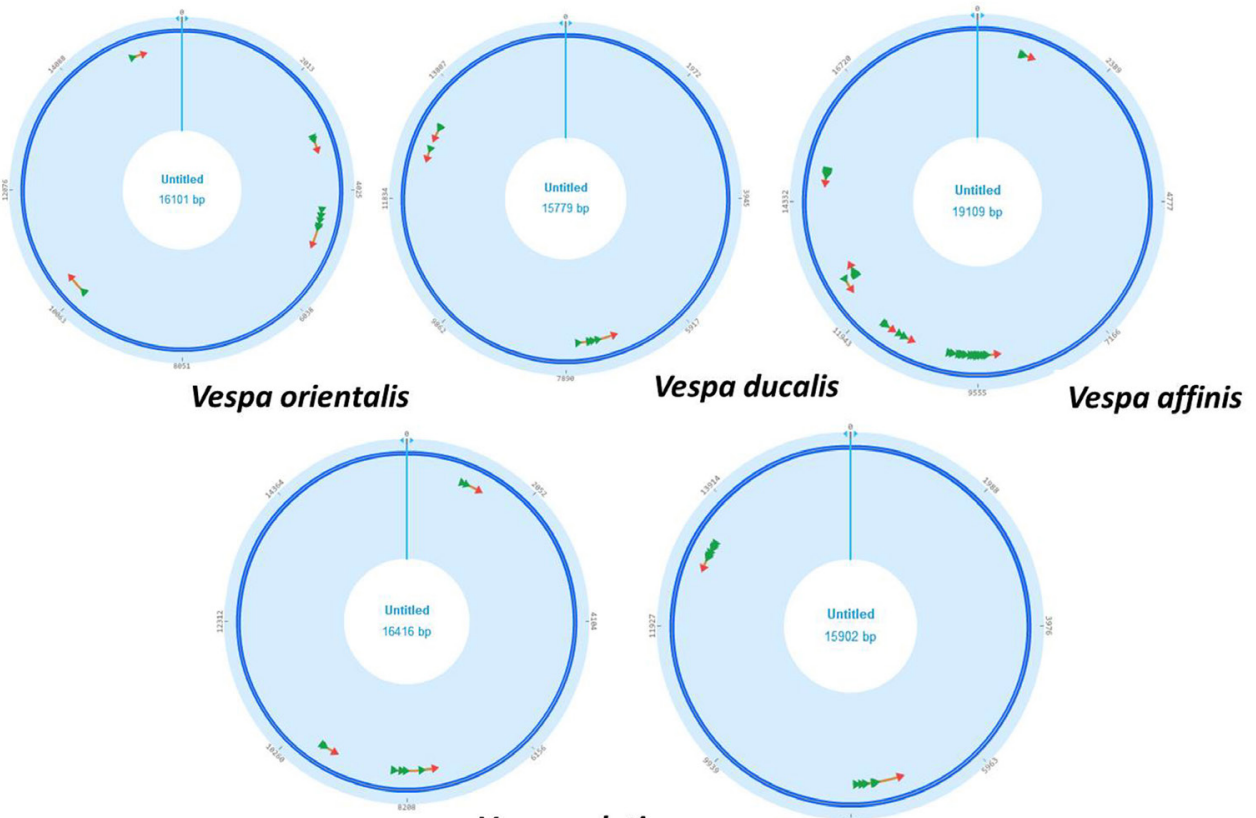

Vespa velutina

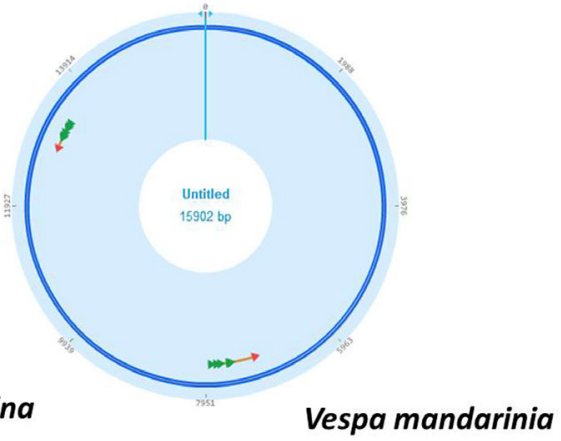

Fig. 3. Open reading frames using Genome Compiler for Vespa orientalis, Vespa ducalis, Vespa affinis, Vespa velutina, and Vespa mandarinia.

\section{Functional analysis}

The shared gene cluster families were 491 among all the five hornets (Fig. 4), and this because all hornets belong to the same family and genus. Indeed, $V$. mandarinia, $V$. velutina, and $V$. ducalis shared 112 gene cluster families (Fig. 4). This supports their close relationships than the other two hornet species. Few shared gene cluster families $(<38)$ were detected between $V$. orientalis and $V$. affinis and the other three hornet species, suggesting lacking of high genetic similarities.

\section{Primers to discriminate between Vespa hornets}

Specific primers were designed to each hornet (Table 1), and tested against amplified region (Fig. 5). These primers can clearly discriminate between these five species, as each primer can give bands only with the target species while no bands can be obtained with the non-target species. 


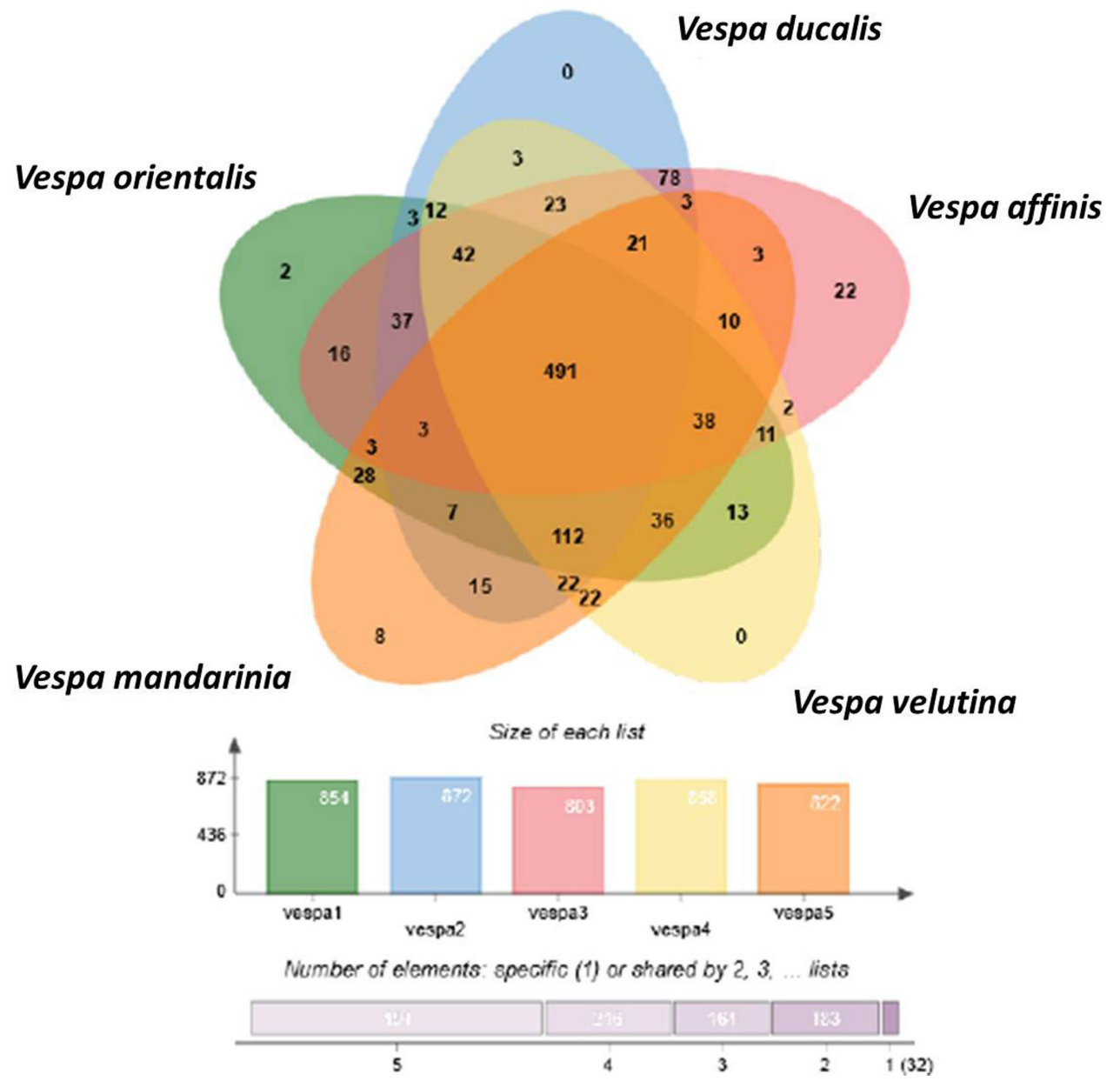

Fig. 4. Gene clusters produced to Vespa orientalis, Vespa ducalis, Vespa affinis, Vespa velutina, and Vespa mandarinia.

\section{CONCLUSION}

The study confirms the close genetic relationships between three Vespa species: $V$. velutina, V. mandarinia and V. ducalis utilizing different analytical techniques. Due to the high genetic similarities detected in this study, it is anticipated that these hornets may be infected with similar pathogens and can host similar pathogens, points which worth further investigations. Especially, some viruses including Israeli acute paralysis virus, deformed wing virus and Moku virus were detected in Vespa hornets (Yañez, Zheng, Hu, Neumann, \& Dietemann, 2012; Garigliany et al, 2017; Forzan, Sagona, Mazzei, \& Felicioli, 2017). Also, the study presented specific primers to discriminate between the five Vespa species: $V$. orientalis, V. ducalis, V. affinis, V. velutina, and V. mandarinia. 
ABOU-SHAARA, H.F., ELBANOBY, M.I.

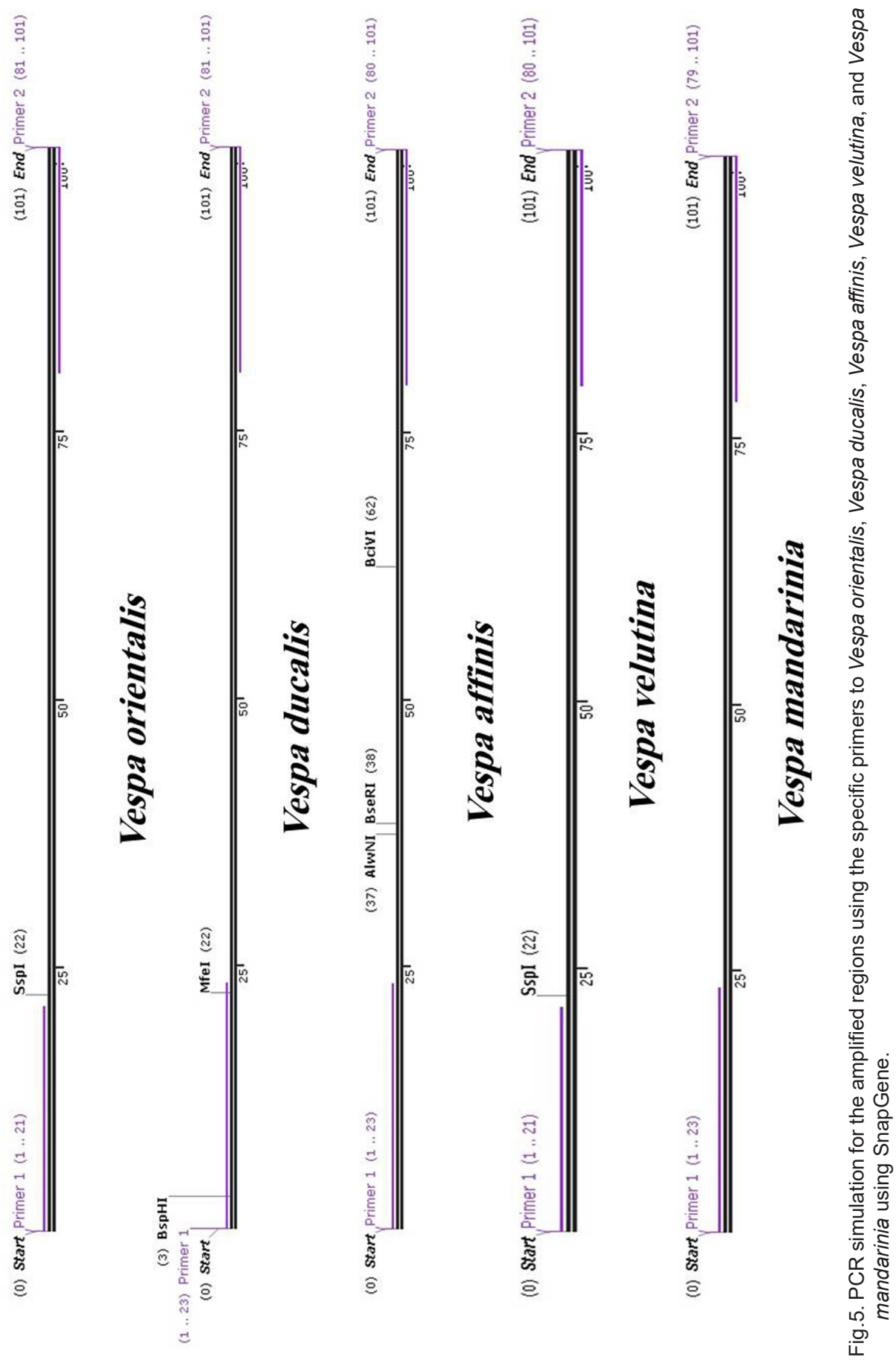


A Bioinformatics Study to Detect the Genetic Characteristics of Vespa Hornets

Table 1. Specific primers to identify Vespa orientalis, Vespa ducalis, Vespa affinis, Vespa velutina, and Vespa mandarinia.

\begin{tabular}{|l|l|l|}
\hline Species & Type & Sequences \\
\hline \multirow{3}{*}{ Vespa orientalis } & Forward 5' & TGAAATTAGGTAGGTATGGAA \\
\cline { 2 - 3 } Vespa ducalis & Reverse 5' & TCCTCCTACAATTCCTAATGT \\
\hline \multirow{3}{*}{ Vespa affinis } & Forward 5' & CTTCATGAAATGTTATCTCATCA \\
\cline { 2 - 3 } & Reverse 5' & AATTCGTTGTGATATAAATGA \\
\hline \multirow{3}{*}{ Vespa velutina } & Forward 5' & TTAATTACAAGAAACTTTATCGG \\
\cline { 2 - 3 } & Reverse 5' & AAATCAACGGCAGGAGAATTGT \\
\hline \multirow{2}{*}{ Vespa mandarinia } & Forward 5' & TAAAAATTCAATTTACTTCAA \\
\cline { 2 - 3 } & Reverse 5' & GTAATCTGAGTAACGTCGTGGG \\
\cline { 2 - 3 } & Reverse 5' & TTAGTAGTATAGGGAATTTCTTG \\
\hline
\end{tabular}

\section{REFERENCES}

Abou-Shaara, H.F. (2019a). Highlights on the genetic relationships between some honey bee viruses using various techniques. Journal of Applied Biotechnology Reports, 6(1), 15-19.

Abou-Shaara, H.F. (2019b). Utilizing bioinformatics to detect genetic similarities between African honey bee subspecies. Journal of Genetics, 98, 96. https://doi.org/10.1007/s12041-019-1145-7.

Abou-Shaara, H.F. \& Bayoumi, S.R. (2019). Using mitochondrial DNA similarity percentages to analyze the maternal source of hybrid bees from two honey bee subspecies. Scientific Papers Animal Science and Biotechnologies, 52(2), 32-40.

Abrol, D.P. (1994). Ecology, behaviour and management of social wasp, Vespa velutina Smith (Hymenoptera: Vespidae), attacking honeybee colonies. Journal of Apiculture, 9, 5-10.

Al-Mahdawi, Q.H. \& Al-Kinani, M.A. (2011). Economical damage of the red wasp Vespa orientalis and yellow wasp Polistes olivaceus on grapes. Diyala Agricultural Sciences Journal, 3, 216-222.

Archer, M.E. (2012). Vespine wasps of the world: behavior, ecology \& taxonomy of the Vespinae. Manchester: Siri Scientific Press, 352 pp.

Bacandritsos, N., Papanastasiou, I., Saitanis, C. \& Roinioti, E. (2006). Three non-toxic insect traps useful in trapping wasps enemies of honey bees. Bulletin of Insectology, 59, 135-145.

Chen, P.Y., Wei, S.J., \& Liu, J.X. (2016). The mitochondrial genome of the Vespa mandarinia Smith (Hymenoptera: Vespidae: Vespinae) and a phylogenetic analysis of the Vespoidea. Mitochondrial DNA Part A, 27, 4414-4415.

Dvořák, L. (2006). Oriental hornet Vespa orientalis Linnaeus, 1771 found in Mexico (Hymenoptera, Vespidae, Vespinae). Entomological Problems, 36, 80.

Edery, H., Ishay, J., Lass, I., \& Gitter, S. (1972). Pharmacological activity of oriental hornet (Vespa orientalis) venom. Toxicon, 10, 13-23. 
Forzan, M., Sagona, S., Mazzei, M., \& Felicioli, A. (2017). Detection of deformed wing virus in Vespa crabro. Bulletin of Insectology, 70, 261-265.

Garigliany, M., Taminiau, B., El Agrebi, N., Cadar, D., Gilliaux, G., Hue, M., Desmecht, D., Daube, G., Linden, A., Farnir, F., De Proft, M., \& Saegerman C. (2017). Moku Virus in invasive Asian hornets, Belgium, 2016. Emerging Infectious Diseases Journal, 23, 2109-2112.

Grosso-Silva, J.M. \& Maia, M. (2012). Vespa velutina Lepeletier, 1836 (Hymenoptera, Vespidae), new species for Portugal. Arquivos Entomolóxicos, 6, 53-54.

Haddad, N., Fuchs, S., Haddaden, J., \& Kopelke, J.P. (2005). Record of Sphecophaga vesparum Curtis, a natural enemy of the Vespa orientalis in the northern part of Jordan. Zoology in the Middle East, 35, 114-116.

Haddad, N.J., Al-Nakeeb, K., Petersen, B., Dalén, L., Blom, N., \& Sicheritz-Pontén, T. (2017). Complete mitochondrial genome of the Oriental hornet, Vespa orientalis F. (Hymenoptera: Vespidae). Mitochondrial Dna Part B, 2, 139-140.

Haim, B., Rimon, A., Ishay, J.S., \& Rimon, S. (1999). Purification, characterization and anticoagulant activity of a proteolytic enzyme from Vespa orientalis venom. Toxicon, 37, 825-829.

Ikan, R., Gottlieb, R., Bergmann, E.D., \& Ishay, J. (1969). The pheromone of the queen of the oriental hornet, Vespa orientalis. Journal of Insect Physiology, 15, 1709-1712.

Ishay, I., Ikan, R., \& Bergmann, E.D. (1965). The presence of pheromones in the Oriental hornet, Vespa orientalis F. Journal of Insect Physiology, 11, 1307-1309.

Ishay, J. (1976). Comb bulding by the oriental hornet (Vespa orientalis). Animal Behaviour, 24, 72-83.

Ishay, J.S., Abes, A.H., Chernobrov, H.L., Barenholz-Paniry, V., Parmet, Y., \& Fuchs, C. (1995). Building activity and longevity of queenless groups of the Oriental hornet, Vespa orientalis. Bulletin of Mathematical Biology, 57, 441-460.

Jukes, T.H. \& Cantor, C.R. (1969). Evolution of protein molecules. In H.N., Munro (Ed.). Mammalian Protein Metabolism (pp. 21-132), Academic Press, New York.

Kim, J.S., Jeong, J.S., Jeong, S.Y., Kim, M.J., \& Kim, I. (2017). Complete mitochondrial genome of the black-tailed hornet, Vespa ducalis (Hymenoptera: Vespidae): Genomic comparisons in Vespoidea. Entomological Research, 47, 129-136.

Kugler, J., Motro, M., \& Ishay, J.S. (1979). Comb building abilities of Vespa orientalis L. queenless workers. Insectes Sociaux, 26, 147-153.

Kumar, S., Stecher, G., \& Tamura, K. (2016). MEGA7: Molecular Evolutionary Genetics Analysis version 7.0 for bigger datasets. Molecular Biology and Evolution, 33, 1870-1874.

López, S., González, M., \& Goldarazena, A. (2011). Vespa velutina lepeletier, 1836 (Hymenoptera: Vespidae): first records in Iberian Peninsula. EPPO Bulletin, 41, 439-441.

Mahdi, H.A., Glaiim, M.K., \& Ibrahim, H.A. (2008). Testing the efficacy of some methods recommended abroad for controlling the oriental hornet, Vespa orientalis L., attacking honey bee, Apis mellifera L., colonies in Iraq. Bulletin of the Iraq Natural History Museum, 10, 21-27.

Matsuura, M. \& Sakagami, S.F. (1973). A bionomic sketch of the giant hornet, Vespa mandarinia, a serious pest for Japanese apiculture (With 12 Text-figures and 5 Tables). Journal of the Faculty of Science Hokkaido University, 19, 125-162.

Monceau, K., Bonnard, O., \& Thiéry, D. (2014). Vespa velutina: a new invasive predator of honeybees in Europe. Journal of Pest Science, 87, 1-16.

Okuyama, H., Martin, S.J., \& Takahashi, J.I. (2017). Complete mitochondrial DNA sequence of the tropical hornet Vespa affinis (Insecta, Hymenoptera). Mitochondrial DNA Part B, 2, 776-777.

Papachristoforou, A., Rortais, A., Sueur, J., \& Arnold, G. (2011). Attack or retreat: contrasted defensive tactics used by Cyprian honeybee colonies under attack from hornets. Behavioural Processes, 86, 236-241? 


\section{A Bioinformatics Study to Detect the Genetic Characteristics of Vespa Hornets}

Papachristoforou, A., Sueur, J., Rortais, A., Angelopoulos, S., Thrasyvoulou, A., \& Arnold, G. (2008). High frequency sounds produced by Cyprian honeybees Apis mellifera cypria when confronting their predator, the Oriental hornet Vespa orientalis. Apidologie, 39, 468-474.

Perrard, A., Pickett, KM., Villemant, C., Kojima, J.I., \& Carpenter, J. (2013). Phylogeny of hornets: a total evidence approach (Hymenoptera, Vespidae, Vespinae, Vespa). Journal of Hymenoptera Research, 32, $1-15$.

Raina, S. \& Singh, V.K. (1996). Asymmetric synthesis of 5-hexadecanolide, pheromone of the queen of the Oriental hornet, Vespa orientalis. Tetrahedron, 52, 4479-4484.

Rosenberg, P., Ishay, J., \& Gitter, S. (1977). Phospholipases A and B activities of the Oriental hornet (Vespa orientalis) venom and venom apparatus. Toxicon, 15, 141-155.

Schoeters, E. \& Billen, J. (1995). Morphology and ultrastructure of a secretory region enclosed by the venom reservoir in social wasps (Insecta, Hymenoptera). Zoomorphology, 115, 63-71.

Sugahara, M. \& Sakamoto, F. (2009). Heat and carbon dioxide generated by honeybees jointly act to kill hornets. Naturwissenschaften, 96, 1133-1136.

Sukpraser, T.S., Rungsa, P., Uawonggul, N., Incamnoi, P., Thammasirirak, S., Daduang, J., \& Daduang, S. (2013). Purification and structural characterisation of phospholipase A1 (Vespapase, Ves a 1) from Thai banded tiger wasp (Vespa affinis) venom. Toxicon, 61, 151-164.

Taha, A.A. (2014). Effect of some climatic factors on the seasonal activity of oriental wasp, Vespa orientalis L. attacking honeybee colonies in Dakahlia Governorate, Egypt. Egyptian Journal of Agricultural Research, 92, 43-50.

Takahashi, J.I., Akimoto, S.I., Hasegawa, E., \& Nakamura, J. (2002). Queen mating frequencies and genetic relatedness between workers in the hornet Vespa ducalis (Hymenoptera: Vespidae). Applied Entomology and Zoology, 37, 481-486.

Takahashi, R., Okuyama, H., Minoshima, Y.N., \& Takahashi, J.I. (2018). Complete mitochondrial DNA sequence of the alien hornet Vespa velutina (Insecta: Hymenoptera) invading Kyushu Island, Japan. Mitochondrial DNA Part B, 3, 179-181.

Tan, K., Radloff, S.E., Li, J.J., Hepburn, H.R., Yang, M.X., Zhang, L.J., \& Neumann, P. (2007). Bee-hawking by the wasp, Vespa velutina, on the honeybees Apis cerana and A. mellifera. Naturwissenschaften, 94, 469-472.

Yañez, O., Zheng, H.Q., Hu, F.L., Neumann, P., \& Dietemann, V. (2012). A scientific note on Israeli acute paralysis virus infection of Eastern honeybee Apis cerana and vespine predator Vespa velutina. Apidologie, 43, 587-589.

Zhang, Q.H., Huang, P., Chen, B., \& Li, T.J. (2018). The complete mitochondrial genome of Orancistrocerus aterrimus aterrimus and comparative analysis in the family Vespidae (Hymenoptera, Vespidae, Eumeninae). ZooKeys, 790, 127-144. 